\title{
Prevalência de marcadores sorológicos de hepatite B numa pequena comunidade rural do Estado de São Paulo, Brasil ${ }^{*}$
}

\author{
Prevalence of serological markers of hepatitis $B$ in a small rural community of \\ S. Paulo State, Brazil
}

Afonso D.C. Passos"*, Uilho A. Gomes*", José F. de C. Figueiredo ***, Margarida M. P. do Nascimento"**, Jacqueline M. de Oliveira"**, Ana M. C. Gaspar***, Clara F. T. Yoshida***

\begin{abstract}
PASSOS, A. D. C. et al. Prevalência de marcadores sorológicos de hepatite B numa pequena comunidade rural do Estado de São Paulo, Brasil. Rev. Saúde públ., S. Paulo, 26: 119-24, 1992. Foi realizado estudo epidemiológico com vistas a determinar a prevalência de marcadores sorológicos de hepatite B na população de um pequeno município, de características rurais, do Estado de São Paulo. Observou-se prevalência total de marcadores igual a 7,74\%, com valores de HBsAg, anti-HBs e anti-HBc, respectivamente iguais a $0,10 \%, 1,69 \%$ e $7,64 \%$. Ressalta-se a importância da determinação do anti-HBc cm estudos epidemiológicos, bem como discute-se a relevância de se comparar a reduzida circulação viral, observada na área, com as clevadas prevalências verificadas em outras regiões, buscando assim levantar hipóleses acerca de mecanismos altemativos de transmissão.
\end{abstract}

Descritores: Hepatite B, epidemiologia. Estudos de prevalência. População rural.

\section{Introdução}

Entre os inúmeros aspectos ainda não totalmente entendidos na história natural da hepatice B, destaca-se a grande variação existente na distribuição de marcadores específicos em populações diversas, às vezes semelhantes entre si no que diz respeito a características gerais ${ }^{6}$. A tentativa de aclarar cstas variações exige a realização de estudos de campo em larga escala, abrangendo populações variadas em sua composição e características sociais $\mathrm{e} \mathrm{cm}$ diferentes situações gcográficas ${ }^{19}$. Estudos de prevalência em amostras populacionais representativas, contudo, praticamente inexistem no Brasil, onde a quase totalidade dos dados disponíveis se refere a grupos restritos $1,8,10,13,16,17,20,23$. Dificulta-se com isso não apenas a gencralização dos acha-

* Parte da lese de doutorado apresentada ao Departamento de Medicina Social da Faculdade de Medicina de Ribeirão Preto da Universidade de São Paulo, 1991.

** Departamento de Medicina Social da Faculdade de Medicina de Ribeirão l'reto - Ribeirāo Preto, Sl' - Brasil

*** Departamento de Clínica Médica da Faculdade de Medicina de Ribeirão Preto - Ribcirão Preto, SP - Brasil

**** Centro de Referência Nacional para Ilepatites Virais. FIOCRUZ. Rio de Janeiro, RJ - Brasil

Separatas/Reprints: A. D. C. Passos - Av, Bandeirantes, 3900 14049-900 - Ribcirão Preto, SP - Brasil

Publicação financiada pela FAPESP. Processo Saúde Colctiva 91/4994-0 dos, mas também a possibilidade de que os mesmos possam ser comparados.

A necessidade de cstudo de prevalência faz-se sentir de modo particular em pequenas comunidades situadas $\mathrm{cm}$ regiōes afastadas dos grandes centros, a respeito das quais muito pouco se conhece no que se refere à situação epidemiológica da hepalte B. Visando caracterizar alguns aspectos da história natural desta doença, em tais situações, foi realizado estudo de campo englobando cerca de $70 \%$ da população de Cássia dos Coqueiros, um pequeno município de 2.800 habitantes, com características rurais, siluado a $80 \mathrm{Km}$ de Ribeirão Prcto, no Estado de São Paulo. Um dos objetivos do estudo consistiu na determinação da prevalência de marcadores sorológicos de hepatite B nos habitantes daquela comunidade, constituindo os seus achados o motivo do presente trabalho.

\section{Material e Método}

Toda a população do Município de Cássia dos Coqueiros foi inicialmente visitada $\mathrm{cm}$ agosto/ sclembro de 1986, ocasião cm que se procedcu a uma atualização do cadastro de moradores, e em que inúmeras informações concernentes às residências foram coletadas. No período de outubro de 1986 a maio de 1990 os indivíduos cadastrados e com idade igual ou superior a um ano foram chamados ao Centro de Saúde daquele Município (no caso de moradores urbanos) ou re-visitados (habitantes rurais) 
para que, caso desejassem, fossem incluidos no estudo após tomarem conhecimento dos seus objetivos e dos procedimentos que seriam adotados.

A cada indivíduo incluído na investigação foi aplicado um questionário específico, visando levantar diferentes fatores de risco para hepatite B. Simultaneamente, foi coletada uma amostra de $10 \mathrm{ml}$ de sangue por punção venosa cubital. $O$ soro de cada indivíduo foi submetido a exames imunocnzimáticos para detecção de HBsAg, anti-HBs e anti$\mathrm{HBc}$ total, utilizando-se para isso de reagentes produzidos e cedidos pelo Centro de Referência Nacional para Hepatites Virais (CRNHV), da Fundação Instituto Oswaldo Cruz. A detecçìo de HBsAg e anti-HBs foi feita por meio de ensaio imunoenzimático indireto ${ }^{7,22}$, utilizando-se para leitura um espectrofotômetro Minireader 2. O ponto de corte foi definido multiplicando-se a média das densidades ópticas dos controles negativos por 2,1 . Assim, foram consideradas, respectivamente como positivas e negativas, as amostras que se situassem acima e abaixo do valor assim obtido. A detcrminação do anti-HBc total foi feita por mcio de cnsaio imunoenzimático de inibição, utilizando-se para leitura dos resultados um espectrofotômetro Minireader 2. O ponto de corte foi calculado pela fórmula:

$$
\frac{\bar{x} \text { cont. pos. }+\bar{x} \text { cont. neg. }}{2}
$$

onde:

$\overline{\mathrm{x}}$ cont. pos. $=$ média da densidade óptica dos controles positivos.

$\overline{\mathrm{x}}$ cont. neg. = média da densidade óplica dos controles negativos.
Os exames de detecção de $\mathrm{HBsAg}$ e anti-HBs foram realizados por uma única pessoa, a qual realiza, de rotina estes procedimentos no Hospital das Clínicas da Faculdade de Medicina de Ribeirão Preto. Os exames de deteç̧̃̃o de anti-HBc total foram realizados por uma funcionária do CRNHV. Todos os exames com resultado acima do "cutoff", dcfinido para a reação, foram repetidos, considerando-se como positivas aquelas amostras que no segundo exame apresentaram tamberm um resultado superior ao ponto de corte.

A análise estatística foi realizada mediante a aplicação do teste qui-quadrado, fixando-se o valor de alfa $=0,05$ como limite de significância para rejeição da hipótese de nulidade.

\section{Resultados}

A Tabcla 1 mostra a distribuição dos indivíduos estudados e da prevalência de marcadores de hepatite $B$ segundo o sexo $\mathrm{c}$ a idade. A prevalência de positivos revela padrões semelhantes nos dois sexos até a faixa dos 35 anos de idade (Figura). Muito cmbora ocorra, após esta faixa etária, tendência de predomínio entre os homens, a qual se acentua mais nitidamente acima dos 65 anos, esta diferença não se revelou estatisticamente significativa - $\left[\mathrm{x}^{2}\right.$ $(8 \mathrm{gl})=10,66 ; \mathrm{p}=0,2217]$.

A Tabcla 2 mostra a distribuição dos marcadores de hepatite B pesquisados, de acordo com a faixa ctária de ocorrência. Apenas dois portadores crônicos de HBsAg foram detectados, um com 38 e outro com 43 anos de idade, resultando numa prevalência total de $0,10 \%$ para este marcador. A

Tabela 1. Distribuição da amostra estudada $\theta$ da prevalência de marcadores sorológicos de hepatite $B$ segundo o sexo $\theta$ a idade.

\begin{tabular}{|c|c|c|c|c|c|c|c|c|c|}
\hline \multirow{2}{*}{$\begin{array}{l}\text { Sexo } \\
\text { Idade }\end{array}$} & \multicolumn{3}{|c|}{ Masculino } & \multicolumn{3}{|c|}{ Feminino } & \multicolumn{3}{|c|}{ Total } \\
\hline & $n$ & + & $\%$ & $n$ & + & $\%$ & $n$ & + & $\%$ \\
\hline $\begin{array}{r}1 \\
5 \\
10-10 \\
15 \\
25-25 \\
25-35 \\
35 \\
45-45 \\
55 \\
>\quad 65 \\
>\quad 65\end{array}$ & $\begin{array}{r}42 \\
125 \\
111 \\
186 \\
160 \\
129 \\
83 \\
83 \\
52\end{array}$ & $\begin{array}{r}2 \\
8 \\
4 \\
11 \\
11 \\
16 \\
9 \\
10 \\
12\end{array}$ & $\begin{array}{r}4,8 \\
6,4 \\
3,6 \\
5,9 \\
6,9 \\
12,4 \\
10,8 \\
12,0 \\
23,1\end{array}$ & $\begin{array}{r}46 \\
86 \\
127 \\
220 \\
176 \\
117 \\
94 \\
76 \\
38\end{array}$ & $\begin{array}{r}-3 \\
8 \\
11 \\
15 \\
8 \\
10 \\
8 \\
5\end{array}$ & $\begin{array}{r}- \\
3,5 \\
6,3 \\
5,0 \\
8,5 \\
6,8 \\
10,6 \\
10,5 \\
13,2\end{array}$ & $\begin{array}{r}88 \\
211 \\
238 \\
406 \\
336 \\
246 \\
177 \\
159 \\
90\end{array}$ & $\begin{array}{r}2 \\
11 \\
12 \\
22 \\
26 \\
24 \\
19 \\
18 \\
17\end{array}$ & $\begin{array}{r}2,3 \\
5,2 \\
5,0 \\
5,4 \\
7,7 \\
9,8 \\
10,7 \\
11,3 \\
18,9\end{array}$ \\
\hline Total & 971 & 83 & 8,5 & 980 & 68 & 6,9 & 1.951 & 151 & 7,7 \\
\hline
\end{tabular}

$n=$ número de individuos incluidos na investigação

$+=$ individuos com um ou mais marcadores presentes 


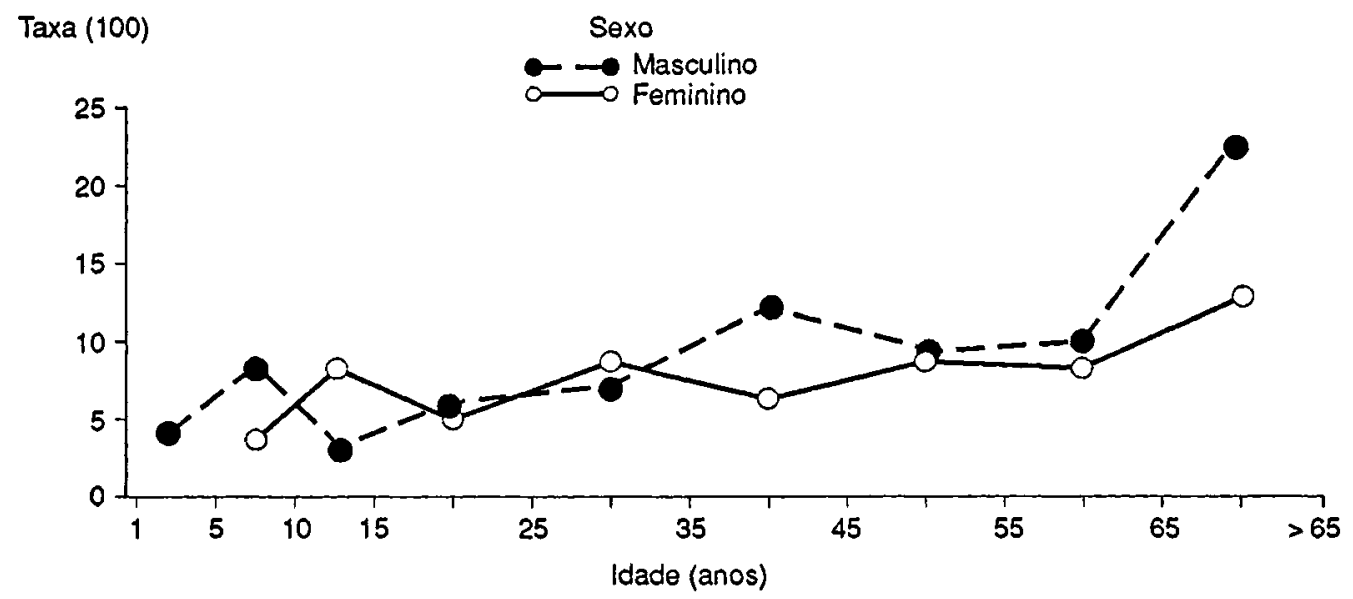

Figura - Prevalência de marcadores sorológicos de hepatite B segundo o sexo e a idade.

Tabela 2. Prevalência de diferentes marcadores sorológicos de hepatite $B$ segundo a idade

\begin{tabular}{|c|c|c|c|c|c|c|c|c|c|}
\hline \multirow[b]{2}{*}{ Idade } & \multirow{2}{*}{$\begin{array}{l}N^{\mathrm{a}} \text { de individuos } \\
\text { estudados }\end{array}$} & \multicolumn{2}{|c|}{$\mathrm{HBsAg}$} & \multicolumn{2}{|c|}{ anti-HBs } & \multicolumn{2}{|c|}{ anti-HBc } & \multicolumn{2}{|c|}{ Total $^{*}$} \\
\hline & & + & $\%$ & + & $\%$ & + & $\%$ & + & $\%$ \\
\hline $\begin{array}{r:r}1 & \vdash \\
5 & -10 \\
10 & -15 \\
15 & -25 \\
25 & -35 \\
35 & -45 \\
45 & -55 \\
55 & -65 \\
>\quad 65\end{array}$ & $\begin{array}{r}88 \\
211 \\
238 \\
406 \\
336 \\
246 \\
177 \\
159 \\
90\end{array}$ & $\begin{array}{l}- \\
- \\
- \\
- \\
\overline{2} \\
- \\
- \\
-\end{array}$ & $\begin{array}{l}- \\
- \\
- \\
- \\
\overline{0}, 8 \\
- \\
- \\
-\end{array}$ & $\begin{array}{l}- \\
- \\
1 \\
7 \\
6 \\
6 \\
4 \\
4 \\
5\end{array}$ & $\begin{array}{l}- \\
- \\
0,4 \\
1,7 \\
1,8 \\
2,4 \\
2,3 \\
2,5 \\
5,6\end{array}$ & $\begin{array}{l}2 \\
11 \\
12 \\
22 \\
26 \\
24 \\
18 \\
18 \\
17\end{array}$ & $\begin{array}{r}2,3 \\
5,2 \\
5,0 \\
5,4 \\
7,7 \\
9,8 \\
10,2 \\
11,3 \\
18,9\end{array}$ & $\begin{array}{l}2 \\
11 \\
12 \\
22 \\
26 \\
24 \\
19 \\
18 \\
17\end{array}$ & $\begin{array}{r}2,3 \\
5,2 \\
5,0 \\
5,4 \\
7,7 \\
9,8 \\
10,7 \\
11,3 \\
18,9\end{array}$ \\
\hline Total & 1.951 & 2 & 0,10 & 33 & 1,69 & 150 & 7,69 & 151 & 7,74 \\
\hline
\end{tabular}

- Individuos com um ou mais marcadores presentes

positividade para o anti-HBs começa a se fazer presente no grupo de 10 a 15 anos, aumentando progressivamente nas idades mais elevadas e perfazendo uma prevalência total de $1,69 \%$. As maiores prevalências são observadas para o anti-HBc total, já presente no grupo de 1 a 5 anos de idade c com tendência claramente ascendente nos grupos etários mais elevados, chegando a atingir um valor máximo de $18,9 \%$ nos individuos acima de 65 anos. A prevalência global deste marcador atinge um valor muito próximo daquele obscrvado para a somatória de todos os marcadores sorológicos presentes, combinados ou isolados $(7,69 \%$ c $7,74 \%$, respectivamente). A análise estatística mostra diferenças significantes nas prevalências de marcadores nas diversas faixas etárias - $\left[\mathrm{x}^{2}(8 \mathrm{gl})=33,20 ; \mathrm{p}=\right.$ $0,0001]$. Embora não representado na tabela, merece ser destacado o fato de que 32 entre os 33 indivíduos com anti-HBs positivo também apresentaram positividade para o anti-HBc.

\section{Discussão}

A positividade dos diferentes marcadores, nas amostras examinadas, revela-se bastante diferenciada do ponto de vista quantitativo (Tabela 2). Enquanto somente dois indivíduos apresentaramse como portadores do antígeno $\mathrm{HBsAg}$, a positividade para o seu anticorpo cspecífico fez-se presente em 33 pessoas. Todavia, o estudo da presença do anti-HBc acrescentou outras 110 amostras à lista dos positivos, atingindo-se assim o total de 151 pessoas $\mathrm{cm}$ que um ou mais marcadores foram detectados. Uma primcira obscrvação que se impōe, portanto, $\mathrm{cm}$ trabalhos de determinação de prevalĉncia, reside na importância de deteç̧ão do anti-HBc. Com efeito o acréscimo deste marcador permiliu ampliar de maneira considerável o conhecimento da siluação da hepatite B na população de estudo, fornecendo uma imagem certamente muito mais aproximada de transmissão e circu- 
lação do agente infeccioso na comunidade. Deve ser lembrado que foram consideradas como positivas apenas as amostras que confirmaram a sua positividade por ocasião de um segundo exame, realizado em todas as que inicialmente mostraram resultado acima do ponto de corte. Este cuidado foi tomado com a finalidade de se cvitar ao máximo a ocorrência de falsos positivos, possibilidade presente de modo especial na determinaçăo do anti-corpo anti-HBc ${ }^{21}$.

Uma segunda observação relevante que pode ser feita a partir destes dados diz respcito aos valores consideravelmente baixos de prevalência $\mathrm{cn}$ contrados em Cássia dos Coqueiros. Critérios internacionalmente aceitos, para definição de padrōes de distribuição de hepatile $B$, consideram como de baixa prevalência árcas que apresentem as seguintes características: a) prevalência de HBsAg entre $0,1 \%$ e $0,5 \%$; b) prevalência de antiHBs entre $4 \%$ e $6 \%$ c c) infecçocs nconatais c na infância ausentes ou raras ${ }^{21}$. Assim, as cifras oblidas em Cássia dos Coqueiros são comparávcis às verificadas fora das populaçôes de risco da América do Norte, Europa Ocidental, Austrália c parte temperada da América do Sul, consideradas como de baixa endemicidade para a doença ${ }^{21}$. Nessas regioes, a história natural da hepatite B apresenta um padrão de circulação onde se destaca a reduzidíssima ou inexistente transmissão vertical, tornando a distribuição da doença um fenômeno esporádico, associado quase que exclusivamente à transmissão por via sexual ou pelo uso de seringas/agulhas contaminadas.

Consequêencia dircta da falta de um considerável reservatório de infectados na população, a raridade ou inexistência de transmissão vertical ocasiona uma distribuição etária característica, com uma positividade que se revela cscassa $\mathrm{cm}$ idades precoces e tende a uma clevação lenta e gradual à medida que aumenta a faixa etária ${ }^{14}$. Este padrão se observa em ambos os sexos na população do presente estudo (Tabela 1 e Figura).

As baixas prevalências de hepatite $B$ fora das tradicionais populações de risco da Amćrica do Norte, Europa Ocidental, Austrália c parte temperada da América do Sul têm sido associadas às melhores condições sócio-econômicas das populaçőes dessas partes do mundo. Considerando-se que essas condiçōes devam ser bastante superiores às verificadas na área do presente estudo, uma questāo que se levanta diz respeito aos mecanismos pelos quais os níveis de endemicidade permanecem semelhantes $\mathrm{cm}$ regiōes tão diferenciadas quanto às condições gerais de vida. Uma possivvel explicação para a baixa cndemicidade em Cássia dos Coqueiros poderia, talvez, scr encontrada em certas características increntes às peque- nas comunidades rurais do interior brasileiro, tais como o relativo isolamento geográfico e a predominância de padrōes de comportamento mais tradicionais c conscrvadorcs. Claro está que apenas isto não serve como explicação totalmente satisfatória, uma vez que elevados niveis de endemicidade também são descritos em pequenas comunidades relativamente isoladas do próprio interior brasileiro, como testemunham os achados entre tribos indigenas e populações nativas da Amazônia $2,3,4,5,9,11,12$. É possível que a condição verificada $\mathrm{cm}$ Cássia dos Coqueiros se deva à combinação de suas características rurais com 0 fato de estar localizada numa macrorregião geográfica (Sudeste) onde a prevalência da doença se situa $\mathrm{em}$ níveis reduzidos, comparativamenie a áreas da Amazônia brasileira ${ }^{13}$.

Achados recentes dando conta de elevadas prevalências em populaçoôcs relativamente isoladas de Iguape e Cananéia, ${ }^{15,18}$ contradizem, à primeira visı, csta explicação. Entretanto, deve ser lembrado que a peculiaridade de uma nítida sobreposição verificada nas distribuiçōes de marcadores de hepatite $B$ e de arboviroses, nessas regioes do Vale do rio Ribcira, sugere que mecanismos de transmissão comuns a estas diferentes doenças possam se fazer presentes na árca, levantando inclusive a hipótese de envolvimento de mosquitos com atividade antropofílica ${ }^{25,18}$.

O presente estudo lança alguma luz sobre a história natural da hepatite B numa situação particular, representada por um pequeno município de características rurais, relativamente isolado, do Estado de São Paulo. A reduzida circulação do vírus, aqui verificada, pode vir a servir como um importante clemento de comparação para outras investigaçð̃es. Assim, o confronto das semelhanças c/ou diferenças entre a população de Cássia dos Coqueiros e as de outros estudos, envolvendo comunidades rurais, pode levantar pistas acerca de possiveis determinantes dos níveis diferenciados de transmissão observados em comunidades variadas. Como exemplo, o flagrante contraste entre a baixa prevalência obtida no presente trabalho e os clevados valores observados em áreas rurais do Vale do Ribcira ${ }^{15,18}$ reforçam a hipótese do envolvimento de insctos antropofílicos na transmissão da hepatite B, nessa região. Com efeito, uma diferença que se destaca entre estas duas áreas rurais é a presença de florestas, abundantes no Vale do Ribcira e ausentes em Cássia dos Coqueiros, acarretando assim densidades desiguais de insetos. Obviamente, comparaçoes deste tipo não definem associações, exigindo-se para isso um aprofundamento nos estudos epidemiológicos que os levem além da mera determinação e comparação de prevalência totais. Isto porque a simples análise 
dos valores de prevalência referentes a toda uma população pode esconder variações internas importantes, eventualmente existentes em segmentos de uma mesma comunidade que difiram entre si no que diz respeito a variáveis tais como a siluação sócio-econômica, procedência, hábitos de vida e cscolaridade, entre outras. Tais comparações, cntretanto, prestam-se a levantar pistas acerca de diferentes fatores passíveis de serem incriminados como envolvidos na transmissão da hepatite $B$.

Deve-se considerar ainda que a prevalência aqui encontrada talvez possa refletir o que se passa $\mathrm{cm}$ situações similares, contribuindo para, eventualmente, reduzir o desconhecimento sobre a epidemiologia da hepatite $\mathrm{B} \mathrm{em}$ comunidades semelhantes a do presente estudo, certamente comuns no interior brasileiro.

PASSOS, A. D. C. et al. [Prevalence of serological markers of hepatitis B in a small rural community of $S$. Paulo State, Brazill. Rev. Saúde públ., S. Paulo, 26: 119-24, 1992. Prevalence of three hepatitis B markers was measured by immunoassay techniques in small rural community of the State of S. Paulo, Brazil. Total prevalence was $7.74 \%$, corresponding to values of $0.10 \%, 1.69 \%$ and $7.74 \%$ for $\mathrm{HBsAg}$, anti-HBs and anti-HBc, respectively. The importance of anti-HBc determination in such studies is stressed. Comparisons between the low viral circulation observed in this area and high prevalences described in other rural communities may contribute to the raising of new hypothesis concerning alternative transmission mechanisms of hepatilis B.

Keywords: Hepatitis B, epidemiology, prevalence studies. Rural population.

\section{Referências Bibliográficas}

1. ABUZW T.; SCHATZMAYR, II. O. Seroepidemiology of hepatitis $A$ and $B$ in two urban communities of Rio de Janciro. Rev.Inst. Med. trop. S. Paulo, 29: 219-23, 1987.

2. ALECRIM, W. D.; MARREIROS, L. S.; ALECRIM, M. G. C.; SANTOS, I. K. F. M. Inquérito sobre presença de HBsAg cm habitantes de Lábrea, Amazonas. [Carta ao Editor]. Rev. Soc. bras. Med. trop., 19: 58-9, 1986.

3. BENSABATHI, G. \& BOSIIELL, J. Presença do antígeno "Austrália" (Au) cm populações do interior do Eistado do Amazonas, Brasil. Rev. Inst. Med. trop. S. Paulo, 15: 284-8, 1973.

4. BENSABATH, G. \& DIAS, L. B. IIepatite de Lábrea (febre negra de Lábrea) e outras hepatites fulminantes cm Sena Madureira, Acre e Boca do Acre, Amazonas, Brasil. Rev. Inst. Med. trop. S. Paulo, 25: 182-94, 1983.

5. BENSABATH, G.; HADLER, S. C.; SOARES, M. C. P.; FIELDS, H.; MAYNARD, J. E. Caractcrísticas serologicas y epidemiologicas de la hepatitis virica aguda en la cuenca amazonica del Brasil. Bol. Ofic. sanil. panamer., 103: 351-62, 1987.

6. BRABIN, L. \& BRABIN, B. Cultural factors and transmisson of hepatitis B virus. Amer. J. Epidem., 122: 725-30, 1985.
7. CAMARGO, I. F.; GASPAR, A. M. C.; YOSHIDA, C. F. $T$. Comparative Elisa reagents for detection of hepatitis B surface antigen (IIBsAg). Mem. Inst. Oswaldo Cruz, 82: $181-7,1987$.

8. IFERRAZ, M. L. G.; VILIELA, M. P.; SILVA, A. E.; PAIVA, E. R. Marcadores sorologicos do virus da hepatite B e anticorpo delta em homossexuais masculinos brasiIeiros. Rev. paul. Med., 103: 228-30, 1985

9. FIGULIREDO-MIENDES, T. A Amazônia Brasileira e a hepatite B. [Editorial]. Mod. Ilepalolol, 14(1): 1-2, 1989.

10. FOCACCIA, R; VERONESI, R.; TAKEDA, A; BAZONE, J. R. C.; RODRIGUES, E.; MAZZA, C. C.; KIMURA, R. T.; FELDMAN, C. Prevalência do antígeno de superfícic do virus da hepatite $B(I B s \wedge g$ ) e seu anticorpo (anti-IlBs) $\mathrm{cm}$ pacientes internados em dois hospitais psiquiátricos. Rev. Inst. Med. trop. S. Paulo, 24: 385-7, 1982.

11. TONSECA, J. C. F. Hepatite B no Estado do Amazonas. Mod. /lepatol., 14(1): 33-5, 1989.

12. FONSECA, J. C. F. \& TAVARES, A. M. Estudo dos marcadores sorológicos do virus da hepatite B (VIIB) em área de ocorrência da hepatite de Lábrea (Febre Negra), Codajás, AM, Brasil. [Canas ao editor]. Rev. Soc. bras. Med. trop., 19: 117, 1986.

13. IIADLER, S. C.; IFAY, O. Il:; PINIIEIRO, F.; MAY. NARD, J. E. La hepatitis en las Americas: informe del grupo colaborador de la Ol'S. Bol. Ofici. sanit. panamer., 103: 185-209, 1987.

14. IIEPA'TITIS virica en la region. Bol. Ofic. sanil, panamer., 100: 330-7, 1986

15. IVERSSON, L. B.; GRANATO, C. F. H.; TRAVASSOS DA ROSA, A.; PANNUT, C. S. Relationship between the prevalenee of antibodies to hepatitis B core antigen and arbovirus in fishermen from the Ribeira Valley, Brasil. Rev. Inst. Med. trop. S. Paulo, 32: 215-20, 1990.

16. MAZZUR, S.; NATH, N.; FANG, C.; BASTIAANS, M. J.; MOLINARIS, J. L.; BALCASER, M.; BEKER, G. S.; BRUNLNGS, E. A.; CAMIRON, A. R. E.; FARREL, V.; FAY, O. H.; LABRADOR-GONZALEZ, G.; GONZALEL, L. G.; GUIIIERREZ, A.; JARAMILLO, T. C.; KATZ, R.; LEME LOPL' $\angle, M$.B.; LEVY-KOENTG, E.; MORALES AYALA, F.; RODRIGUES AMAYA, J.; RODRIGULS-MOYADO, II.; T'ORRES, R. A.; VELASCO, M. Distribuicion de marcadores de virus de hepatitis $B$ (VIHB) en la sange de donadores de 13 paises del hemisfério occidental: aclas del Taller Latinoamericano de la Cruz Roja sobre Hepatius B. Bol. Ofici. sanil. panamer., 89: 239-48, 1980.

17. MNCIS, M.; GULMARĀES, R. X.; NETO, J. F.; NOVO, N. F.;CHECTLR, L. Marcadores imunológicos do víns $B$ da hepatite em alcoólatras e indivíduos normais. Rev. paul. Med., 102: 205-13, 1984.

18. PANNUTI, C. S.; IVERSSON, L. B.; MENDONÇA, J. S.; TRAVASSOS DA ROSA, A. P. A.; GRANATO, C. F. II. Relationship between the prevalence of antibodies to arbovirus and hepatitis $B$ virus in the Vale do Ribcira Region, Brazil. Rev. Inst. Med. trop. S. Paulo, 31: 103. $9,1989$.

19. PASSOS, A. D. C. Estudo cpidemiológico sobre hepatite $B \mathrm{~cm}$ Cássia dos Coquciros, SP, Brasil. Ribcirão Prclo, 1991. [Tese de Doutorado - Faculdade de Medicina de Ribcirāo Preto da USP'].

20. STRAUS, E.; MAIFEI-JR, R. A.; SÁ, M. F. G.; DUTRA, A. P.; TAKEDA, A. K. Incidência de liBsAg e antiHiBs. Freqüência do antígeno de superfície da hepatite B $\mathrm{c}$ de seus anticorpos detectados por radioimunoensaio em pessoal hospitalar. Rev. Inst. Med. trop. S. Paulo, 25: 246-53, 1983. 
21. U. S. DEPARTMENT OF HEALTH AND HUMAN SERVICES. Public Healih Service. Centers for Disease Control. Ilepatitis Surveillance. Adlanta, Ga, 1989. (Report, 52).

22. VOLLER, A.; BARTLETT, A.; BIDWELL, D. E. Enzyme immunoassays with special reference to Elisa techniques. J. clin. Pathol., 31: 507-20, 1978.

23. YOSHIDA, C. F. T.; NOGUEIRA, R. M. R.; MERCADANTE, L. A. C.; PINHÃO, A. T.; SCHATZMAYR,
H. G. Seroepidemiological survey of Hepatitis A and B, Cytomegalovirus and Herpes simplex type 2 in prime blood donors from Rio de Janeiro, Brazil. Rev. Microbiol. S. Paulo, 18: 5-11, 1987.

Recebido para publicação em 29/8/1991 Reapresentado em 22/11/1991 Aprovado para publicaçäo em 6/12/1991 